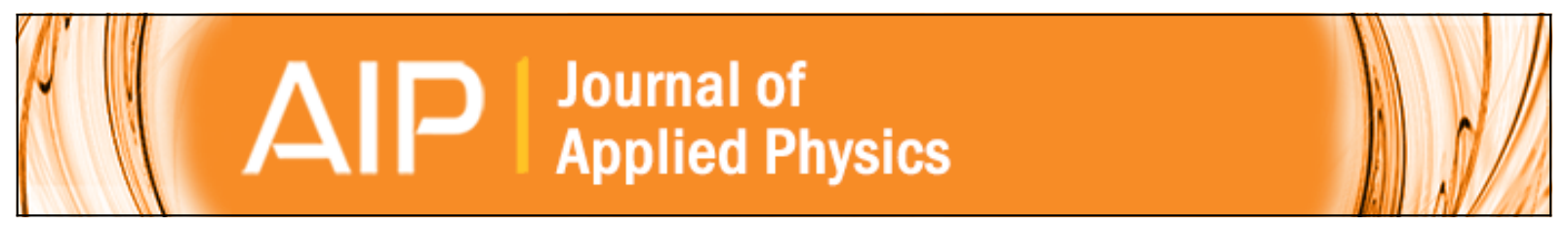

Hydrogen concentration and bonding configuration in polycrystalline diamond films: From micro-to nanometric grain size

Sh. Michaelson, O. Ternyak, R. Akhvlediani, A. Hoffman, A. Lafosse, R. Azria, O. A. Williams, and D. M. Gruen

Citation: Journal of Applied Physics 102, 113516 (2007); doi: 10.1063/1.2818372

View online: http://dx.doi.org/10.1063/1.2818372

View Table of Contents: http://scitation.aip.org/content/aip/journal/jap/102/11 ?ver=pdfcov

Published by the AIP Publishing 


\title{
Hydrogen concentration and bonding configuration in polycrystalline diamond films: From micro-to nanometric grain size
}

\author{
Sh. Michaelson, O. Ternyak, R. Akhvlediani, and A. Hoffman ${ }^{\text {a) }}$ \\ Schulich Faculty of Chemistry, Technion, Israeli Institute of Technology, Haifa 32000, Israel
}

\author{
A. Lafosse and R. Azria \\ Laboratoire des Collisions Atomiques et Moléculaires (UMR 8625, FR LUMAT), Université Paris-Sud \\ and CNRS, Orsay F-91405, France \\ O. A. Williams \\ Institute for Materials Research, Universiteit Hasselt, Wetenschapspark 1, 3590 Diepenbeek, Belgium \\ D. M. Gruen \\ Materials Science Division, Argonne National Laboratory, Illinois 60439, USA
}

(Received 22 August 2007; accepted 5 October 2007; published online 7 December 2007)

\begin{abstract}
The present work studies the incorporation of hydrogen and its bonding configuration in diamond films composed of diamond grains of varying size which were deposited by three different methods: hot filament (HF), microwave (MW), and direct current glow discharge (dc GD) chemical vapor deposition (CVD). The size of diamond grains which constitute the films varies in the following way: hundreds of nanometers in the case of HF CVD ("submicron size," $300 \mathrm{~nm}$ ), tens of nanometers in the case of MW CVD $(3-30 \mathrm{~nm})$, and a few nanometers in the case of dc GD CVD ("ultrananocrystalline diamond," $\sim 5 \mathrm{~nm}$ ). Raman spectroscopy, secondary ion mass spectroscopy, and high resolution electron energy loss spectroscopy (HR-EELS) were applied to investigate the hydrogen trapping in the films. The hydrogen retention of the diamond films increases with decreasing grain size, indicating that most likely, hydrogen is bonded and trapped in grain boundaries as well as on the internal grain surfaces. Raman and HR-EELS analyses show that at least part of this hydrogen is bonded to $s p^{2}$ - and $s p^{3}$-hybridized carbon, thus giving rise to typical $\mathrm{C}-\mathrm{H}$ vibration modes. Both vibrational spectroscopies show the increase of $\left(s p^{2}\right)-\mathrm{C}-\mathrm{H}$ mode intensity in transition from submicron to ultrananocrystalline grain size. The impact of diamond grain size on the shape of the Raman and HR-EELS hydrogenated diamond spectra is reported and discussed. () 2007 American Institute of Physics. [DOI: 10.1063/1.2818372]
\end{abstract}

\section{INTRODUCTION}

The carbon science and technology has developed extensively in the last few decades due to discoveries of various polycrystalline diamond film deposition methods, synthesis of nanotubes, fullerenes, carbon fibers, etc. Nanocrystalline diamond films represent a new remarkable material that attracts a lot of attention of the scientific world due to its promising potential in many possible applications, such as tribology, ${ }^{1,2}$ field emission, ${ }^{3,4}$ electrochemistry, ${ }^{5,6}$ protective optical windows ${ }^{7,8}$ as well as its unique ability to incorporate $n$-type dopants ${ }^{9}$ compared to microcrystalline and single crystal diamond.

The microstructure and properties of carbon-based thin films depend on the deposition process and conditions used, including pressure, gas phase composition, and substrate temperature, as well as the energy of the reactive species (atoms or ions). Nanodiamond films may be deposited by a number of deposition processes, which differ in the growth species and deposition parameters. In fact, each method results in different types of nanodiamond films. These may differ in terms of the diamond particle size, grain boundary

\footnotetext{
a) Author to whom correspondence should be addressed. Electronic mail: choffman@tx.technion.ac.il.
}

nature, hydrogen content, defect density, amorphous or graphitic component of the films, morphological properties of the films, and different chemical and physical properties. Also, the formation mechanisms of the different films are dis-similar. For example, the growth of nanodiamond films deposited by microwave (MW) chemical vapor deposition (CVD) from Ar-rich plasma was suggested to occur from $\mathrm{C}_{2}$ dimers on the film surface, ${ }^{10}$ whereas deposition from hydrogen-rich direct current $(\mathrm{dc})$ energetic plasma is a subsurface or subplantation process. ${ }^{11}$

The ability to deposit diamond films with nanoscale ordered surfaces and defined crystalline size is crucial for possible practical applications. The well-known negative electron affinity and high conductivity of diamond surfaces are properties of fully hydrogenated diamond surfaces. ${ }^{12-14}$ Similarly, diamond grain size may influence the electronic and optical properties of the films. ${ }^{15-18}$ The properties and associated practical applications of diamond films are significantly modified by their surface structure and chemical composition. However, the chemical and physical characterization of the uppermost surface atomic layers of diamond films presents a great challenge. Common surface sensitive techniques [x-ray photoelectron spectroscopy (XPS), Auger electron spectroscopy (AES), electron energy loss spectroscopy 
(EELS), etc.] usually deal with a few nanometer surface region rather than with atomic monolayer coverage. Similarly, the characterization of diamond grain size (especially in nanometric scale) requires the use of complicated transmission electron microscopy (TEM) usually combined with x-ray diffraction analysis. Therefore, the quest of additional complementary techniques providing information about the grain size and surface properties is of high importance.

In our previous studies related to hydrogen concentration and bonding configuration on the surface and within diamond films, we applied vibrational spectroscopy and secondary ion mass spectroscopy. ${ }^{19,20}$ Hydrogen is a key component of the gas mixture usually used for diamond nucleation and growth by CVD methods. It is, thus, involved in many different processes related to diamond nucleation and growth including (1) formation of clusters necessary for growth $\left(\mathrm{CH}_{x}\right.$ or $\left.\mathrm{C}_{2} \mathrm{H}_{x}\right)$, (2) stabilization of diamond clusters and surfaces, (3) preferential etching and removal of nondiamond constituents, and (4) abstraction of hydrogen from the diamond surface to allow incorporation of additional $\mathrm{C}$ containing growth species. In the case of nanodiamond films deposited from energetic species, hydrogen is physically incorporated into the films and most likely it stabilizes the nanodiamond phase. ${ }^{11}$ It is no wonder that the hydrogen must be incorporated in some quantity in diamond films and the questions to be asked are (1) in what quantities, (2) in what locations [in the grains as interstitials, forming defect- $\mathrm{H}$ clusters in the grains, on the diamond surfaces, in grain boundaries, and in a nondiamond constituent between the grains (e.g., when nanodiamond crystallites are embedded in an $a$-C/graphitic matrix)], and (3) in what bonding configuration.

The presence of $\mathrm{H}$ in diamond lattice has serious repercussion on its characteristics. ${ }^{21}$ While hydrogen incorporation and effects in hydrogenated amorphous carbon films, which may contain up to 45 at $\%$ hydrogen, ${ }^{22}$ are relatively well studied, ${ }^{22-27}$ only little information is available on hydrogen distribution, concentration, and location in diamond films. ${ }^{21,28-31}$ Fourier transform infrared absorption and elastic recoil detection analysis (ERDA) were used to evaluate the location of hydrogen in diamond. It has been found that the hydrogen in CVD diamond is incorporated in both grain boundaries ${ }^{19-21,30}$ [on diamond surfaces and in nondiamond (graphitic and amorphous carbon) regions] and also is trapped in grain defects. ${ }^{31}$

In this paper, we investigate the hydrogen concentration and bonding configuration in diamond films of varying grain size. ${ }^{19,32-34}$ The films consist of diamond crystallites of sizes from $\sim 5$ to $\sim 300 \mathrm{~nm}$ depending on deposition methods and conditions. ${ }^{11,33,34}$ The thickness of continuous films varies from $\sim 70$ to $\sim 1000 \mathrm{~nm}$ depending on deposition time. The investigated diamond films were grown by three different kinds of CVD methods: (1) hot filament (HF) CVD, (2) direct current glow discharge (dc GD) CVD and (3) MW CVD. The first two methods utilize hydrogen rich gas mixtures $\left(\mathrm{CH}_{4} / \mathrm{H}_{2}\right.$ ratios were $1 / 99$ and $9 / 91$ correspondingly), while the third one uses a plasma mostly comprised of Ar gas $(>95 \%)$ while hydrogen atoms originate mainly from meth- ane species. The three investigated kinds of diamond films, grown by different techniques, have different microstructures and phase compositions.

\section{EXPERIMENTAL}

\section{A. The polycrystalline diamond films: Brief description of deposition methods and microstructure of the films}

Three kinds of CVD diamond films were grown on silicon substrates by different methods. Below, the main differences in the deposition method, growth mechanism and film microstructure are briefly discussed.

(1) MW CVD nanodiamond films were grown from a hydrogen poor gas mixture. ${ }^{34}$ The films were grown on $\mathrm{Si}$ substrates maintained at $800{ }^{\circ} \mathrm{C}$ using a microwave power of $1200 \mathrm{~W}$ and total gas pressure of 200 Torr. Prior to deposition the silicon substrates were seeded mechanically in solution with diamond powder. Two gas mixtures were used to deposit nanodiamond films. (i) $1.4 \% \mathrm{CH}_{4}$ and $98.6 \% \mathrm{Ar}$, in this case, the growth rate is $0.96 \mu \mathrm{m} / \mathrm{h}$ and diamond grain size is $3-20 \mathrm{~nm}$ (film labeled MW-CVD-3-20 nm). (ii) $1.4 \% \mathrm{CH}_{4}, 1 \% \mathrm{H}_{2}$, and $97.6 \% \mathrm{Ar}$, in this case, the growth rate is $2.7 \mu \mathrm{m} / \mathrm{h}$ and grain size is $10-30 \mathrm{~nm}$ (film labeled MW-CVD$10-30 \mathrm{~nm}){ }^{34}$ The mechanism of the film formation was investigated to a great extent ${ }^{10}$ and is considered as a surface process occurring from $\mathrm{C}_{2}$ molecule as the main growth species. Nanodiamond film growth from $\mathrm{C}_{2}$ species requires a surface pretreatment aimed to introduce diamond growth centers onto which the film grows. The as-deposited films are characterized by a high $s p^{3}$ content of $\sim 95 \%$ and nanometric grain size ${ }^{10}$ (in the present study, in the range of 3-30 nm), homogeneously distributed over the whole thickness.

(2) HF CVD diamond films were grown from a hydrogen rich gas mixture $\left(\mathrm{CH}_{4} / \mathrm{H}_{2}\right.$ ratio was 1/99). The evolution of the film occurs on nucleation centers immersed into the substrate by ultrasonic abrasion with polydispersed mixed diamond slurry. ${ }^{33}$ This pretreatment results in an initial diamond particle density (DPD) of $\sim 5$ $\times 10^{10} \mathrm{~cm}^{-2}$. This high DPD value allows deposition of continuous films with a minimal thickness of $\sim 70-100 \mathrm{~nm} .{ }^{15,33}$ The nucleation is a surface process, while the main growth species are $\mathrm{CH}_{x}$ and hydrogen radicals. The diamond growth occurs on nucleation centers, which gradually merge and coalesce into continuous film. The crystal size evolves from $\sim 50-70 \mathrm{~nm}$ in the nearly coalescent film $[\sim 100 \mathrm{~nm}$ film thickness, $\sim 10$ min deposition, Fig. 1(a)] and reaches nearly a constant value of $300-400 \mathrm{~nm}$ in micron thick films [deposition time of $\sim 1$ h, Fig. 1(b)]. The increased crystalline size observed in the high resolution scanning electron microscopy (HR-SEM) images (Fig. 1) is a result of the suppression of small crystallites by fast growing crystallites which comprise the faceted surface. All the deposited films are characterized by high diamond quality $\left(>98 \% s p^{3}\right)$ and well-defined diamond facets.

(3) dc GD CVD films were grown from hydrogen rich 

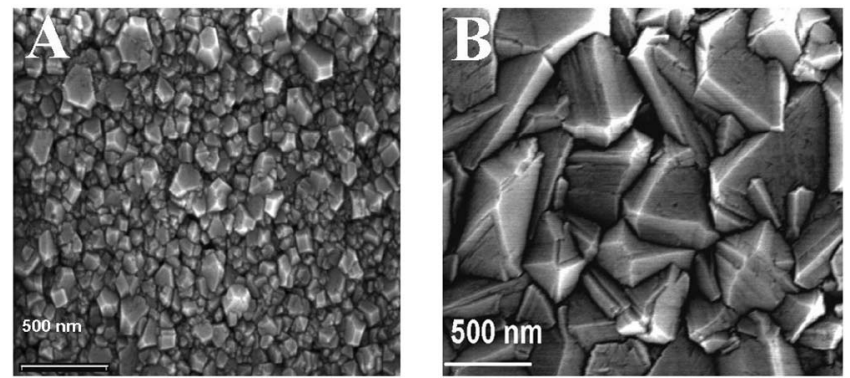

FIG. 1. HR-SEM micrographs of as-deposited HF CVD diamond films: (a) film deposited from $\mathrm{CH}_{4}+\mathrm{H}_{2}$ gas mixture for 10 min (thickness of $\sim 100 \mathrm{~nm}$, grain size of $\sim 50-70 \mathrm{~nm}$ ) and (b) film deposited from $\mathrm{CH}_{4}$ $+\mathrm{H}_{2}$ gas mixture for $60 \mathrm{~min}$ (thickness of $\sim 700 \mathrm{~nm}$, grain size of $\sim 300 \mathrm{~nm}$ ).

plasma $\left(\mathrm{CH}_{4} / \mathrm{H}_{2}\right.$ ratio was $\left.9 / 91\right)$ by means of continuous substrate bombardment by positive hydrocarbon and hydrogen ions of $\sim 100-200 \mathrm{eV}$ kinetic energy. ${ }^{11,32}$ No pretreatment procedure is needed to induce diamond nucleation. The nanodiamond growth occurs in the subsurface region of the film resulting in the upper surface region consisting of hydrogenated amorphous carbon. The film evolves on top of a hydrogenated carbonaceous precursor containing a mixture of an amorphous and graphitic carbon formed during the first $\sim 20 \mathrm{~min}$ of deposition ( $\sim 300 \mathrm{~nm}$ thickness). When the precursor density reaches $\sim 3 \mathrm{~g} / \mathrm{cm}^{3}$, nanodiamond particles precipitate and grow to a final size of $\sim 5 \mathrm{~nm}$ by means of preferential displacement of loosely bonded carbon atoms by energetic ions. ${ }^{11,32}$ The $s p^{3}$ content of the film grown for $1 \mathrm{~h}$ reaches $\sim 80 \%$. The nanodiamond particles are embedded in hydrogenated amorphous carbon matrix. Table I summarizes the deposition methods and the resulting grain size of all the investigated diamond films.

\section{B. Experimental methods}

The hydrogen concentration within the three different kinds of polycrystalline diamond films described above were analyzed by secondary ion mass spectroscopy (SIMS) technique. ${ }^{19,35}$ SIMS analysis was carried out in a dynamic mode in a Cameca IMS4f ion microscope using a $14.5 \mathrm{keV}$ $\mathrm{Cs}^{+}$ion beam. The sampling area was about $64 \mu \mathrm{m}^{2}$. The basic chamber pressure was $8 \times 10^{-10}$ Torr, while the ion current was about $1 \times 10^{-8} \mathrm{~A}$.

The Raman measurements were carried out using a DILOR XY system. The measurements were performed using the Ar line at $514.5 \mathrm{~nm}$ in a backscattering geometry. The laser beam spot size was $\sim 1 \mu \mathrm{m}$ in diameter and the incident power was $10 \mathrm{~mW} .^{20}$

The electron spectroscopy measurements were carried out using an ultrahigh vacuum (UHV) system consisting of two chambers connected in tandem. In the first chamber annealing, XPS and ion irradiation experiments were carried out, whereas the second chamber is dedicated to HR-EELS. The samples can be heated in situ up to $\sim 1000{ }^{\circ} \mathrm{C}$ and exposed to thermally activated hydrogen. The HR-EELS chamber is equipped with a Delta 0.5 spectrometer (VSI-SPECS)
TABLE I. Summary of grain sizes and deposition methods of the investigated diamond films.

\begin{tabular}{llll}
\hline \hline \multicolumn{1}{c}{ Film name } & $\begin{array}{c}\text { Grain } \\
\text { size }(\mathrm{nm})\end{array}$ & \multicolumn{1}{c}{ Deposition method } & $\begin{array}{c}\text { Gas } \\
\text { composition } \\
\left(\mathrm{CH}_{4} / \mathrm{H}_{2} / \mathrm{Ar}\right)\end{array}$ \\
\hline dc-GD-CVD-5 nm & $\sim 5$ & de glow discharge CVD & $9 / 91 / 0$ \\
HF-CVD-300 nm & 300 & Hot filament CVD & $1 / 99 / 0$ \\
MW-CVD-3-20 $\mathrm{nm}^{\mathrm{c}}$ & $3-20$ & Microwave CVD & $1.4 / 0 / 98.6$ \\
MW-CVD-10-30 $\mathrm{nm}^{\mathrm{c}}$ & $10-30$ & Microwave CVD & $1.4 / 1 / 97.6$ \\
\hline \hline
\end{tabular}

${ }^{\mathrm{a}}$ Reference 32 .

${ }^{\mathrm{b}}$ Reference 33.

${ }^{\mathrm{c}}$ Reference 34 .

consisting of a double monochromator and a single analyzer housed in an UHV system with a base pressure of $\sim 8$ $\times 10^{-10}$ Torr. All spectra were recorded up to loss energies of $800 \mathrm{meV}$ at room temperature in the specular geometry with an incident angle of $55^{\circ}$ from the surface normal, incident energy of $5 \mathrm{eV}$, and energy resolution of $5-8 \mathrm{meV}$ [according to full width half maximum (FWHM) of the elastic peak]. The XPS measurements were carried out using $\mathrm{Al} K \alpha$ $(1486.6 \mathrm{eV})$ photon irradiation. The surface quality and phase composition of the films were investigated by $\mathrm{C}(1 s)$ photoelectron energy loss spectra and EELS (plasmon losses) in the reflective mode at primary electron energy of $500 \mathrm{eV}$.

\section{RESULTS AND DISCUSSION}

\section{A. Hydrogen atom concentrations in polycrystalline diamond films as a function of grain size studied by secondary ion mass spectroscopy}

SIMS depth profiles of hydrogen concentration within the different diamond films are shown in Fig. 2. Profile 2(a) was measured for an $\sim 1.6 \mu \mathrm{m}$ thick HF CVD sample grown for $2 \mathrm{~h}$ from $\mathrm{CH}_{4}+\mathrm{H}_{2}$ gas mixture. Its initial grain size (close to the film-Si substrate interface) is $\sim 50 \mathrm{~nm}$ and develops during the deposition to a final grain size of $300-400 \mathrm{~nm}$, thus allowing a direct measurement of the correlation between the hydrogen trapping and the crystalline size. ${ }^{19,35}$ Note that the sampling depth given in Fig. 2 represents the film surface at a depth of 0 and the Si substrate region at a depth of $1.6 \mu \mathrm{m}$. It is very clear that the hydrogen concentration of this film decreases from $6 \times 10^{20}$ at. $/ \mathrm{cm}^{3}$ at the region close to the Si substrate (50 nm grain size) to $1.2 \times 10^{20}$ at. $/ \mathrm{cm}^{3}$ in the region close to the film's surface formed after a deposition time of $\sim 2 \mathrm{~h}(\sim 300 \mathrm{~nm}$ grain size). ${ }^{19,33}$

The profile of hydrogen atoms in dc GD CVD film grown for 1 hour is shown in Fig. 2, curve (b). In our previous works, ${ }^{11,32}$ we showed that the growth of the dc GD CVD film advances through the following stages: (1) graphitic film with its basal plane perpendicular to the substrate, a low $\mathrm{H}$ concentration and low $\left(\sim 2.2 \mathrm{~g} / \mathrm{cm}^{3}\right)$ density, (2) an increase of the density followed by incorporation of hydrogen, and (3) the formation of a dense $\left(\sim 3 \mathrm{~g} / \mathrm{cm}^{3}\right)$, hydrogen rich layer in which diamond nucleates and grows. The hydrogen concentration in the nanodiamond film deposited by dc GD CVD increases from $3.3 \times 10^{21}$ at the nanographitic 


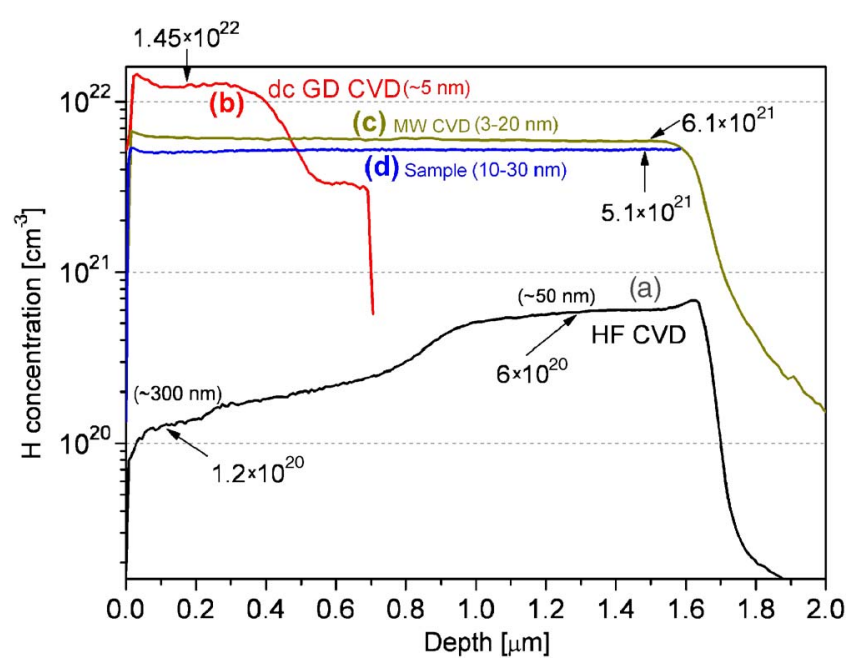

FIG. 2. (Color online) SIMS profile of hydrogen atoms within three different types of diamond films. (a) HF CVD film deposited from $\mathrm{CH}_{4}+\mathrm{H}_{2}$ gas mixture for $2 \mathrm{~h}$. Note the decrease of $\mathrm{H}$ concentration from 6 $\times 10^{20}$ at. $/ \mathrm{cm}^{3}$ at initial growth region (grain size of $\sim 50 \mathrm{~nm}$ ) to 1.2 $\times 10^{20} \mathrm{H} / \mathrm{cm}^{3}$ for thicker film (grain size of $\sim 300 \mathrm{~nm}$ ). (b) $700 \mathrm{~nm}$ thick nanodiamond film deposited by dc GD CVD. The hydrogen concentration increases from $3.3 \times 10^{21}$ at. $/ \mathrm{cm}^{3}$ at the initial stage of film evolution (predominantly graphitic precursor) up to $1.45 \times 10^{22}$ at. $/ \mathrm{cm}^{3}$ in the region where $\sim 5 \mathrm{~nm}$ sized nanodiamond grains are embedded in an amorphous carbon matrix. (c) MW CVD diamond film with grain size of 3-20 nm. (d) MW CVD diamond film with grain size in the range of $10-30 \mathrm{~nm}$.

precursor region to $1.45 \times 10^{22}$ at. $/ \mathrm{cm}^{3}$ in the $\sim 5 \mathrm{~nm}$ sized nanodiamond crystallite region. ${ }^{28}$ The hydrogen concentration depth profile of the dc GD film reflects the evolution of its structure from an initial low density, low hydrogen concentration graphitic film through a medium density, hydrogen containing film until a dense, hydrogen containing matrix evolves, in which $\sim 5 \mathrm{~nm}$ sized nanodiamond crystallites precipitate. Our previous measurements of absolute hydrogen concentration within these films by means of ERDA revealed hydrogen concentration of $15-20$ at. $\%,{ }^{28}$ which confirms the present SIMS measurements.

In Fig. 2, curves (c) and (d) show the hydrogen concentrations in two nanodiamond films deposited by MW CVD with grain size of 3-20 and $10-30 \mathrm{~nm}$, respectively. The measured hydrogen concentrations for samples MW-CVD$3-20 \mathrm{~nm}$ and MW-CVD-10-30 nm were $6.1 \times 10^{21}$ and $5.1 \times 10^{21}$ at. $/ \mathrm{cm}^{3}$, correspondingly. Note the slightly larger hydrogen concentration in MW-CVD-3-20 nm $\left(\mathrm{CH}_{4} / \mathrm{Ar}\right.$ ratio of 1.4/98.6, grain size of 3-20 nm) than in MW-CVD$10-30 \mathrm{~nm}\left(\mathrm{CH}_{4} / \mathrm{H}_{2} / \mathrm{Ar}\right.$ ratio of $1.4 / 1 / 97.6$, grain size of
10-30 nm), e.g., despite the higher hydrogen concentration in the gas phase, its retention within the film is lower for the last sample. Moreover, the hydrogen concentration in MW CVD films (grown from hydrogen poor gas mixture) largely exceeds that measured for the HF CVD grown films (carried out in a hydrogen rich atmosphere). Therefore, one may suggest that the hydrogen incorporation within the diamond film is governed by another factor beyond gas mixture composition. The most evident factor which influences the hydrogen atom retention within the films is diamond grain size. Our results clearly show that the smaller diamond crystallites are, the higher the hydrogen concentration within the films is. Note that all samples were mounted at the same time in the SIMS chamber and measured at the same conditions. Therefore, while the absolute hydrogen concentration values within the films may depend on the correct relative sensitivity factor, the relative measured concentrations can be compared.

Table II summarizes the $\mathrm{H}$ concentrations in the different films, the atomic percentages of $\mathrm{H}$ (assuming a $\mathrm{C}$ density of $10^{23}$ at. $/ \mathrm{cm}^{3}$ ), the crystalline sizes deduced from HR-SEM and HR-TEM, and the surface to volume atom ratios of fcc crystallites with the same crystalline size. It is very clear that the hydrogen concentration in the diamond films increases with decreasing crystalline size. This result strongly suggests that hydrogen atoms decorate the internal grain interface of the bulk diamond films. The trapping of hydrogen in grain boundaries is a natural consequence of the accepted diamond growth mechanism which involves adsorption of a $\mathrm{CH}_{x}$ growth species first and then abstraction of one hydrogen atom from the surface by atomic hydrogen in the gas phase, allowing the diamond carbon atom to be bonded to another $\mathrm{CH}_{x}$ radical. Coalescence of adjacent diamond crystallites most likely does not result in complete hydrogen desorption from touching surfaces, leading to the incorporation of hydrogen on the touching crystallite surfaces (grain boundaries). In the case of nanodiamond film deposition from energetic species, hydrogen stabilizes the nanodiamond grains as discussed in our previous studies. ${ }^{11,32}$

\section{B. The impact of diamond grain size and hydrogen concentration on the shape of the Raman spectra}

Raman spectra of polycrystalline diamond films display the diamond optical phonon line at $1332 \mathrm{~cm}^{-1}$ and other contributions originated in $s p^{2}$-carbon related features (e.g., the

TABLE II. Hydrogen concentration vs the crystalline size and the surface to volume atom ratio.

\begin{tabular}{lcccc}
\hline \hline \multicolumn{1}{c}{ Film type } & $\begin{array}{c}\mathrm{H} \\
\text { concentration } \\
\left(\text { at./ } / \mathrm{cm}^{3}\right)\end{array}$ & $\begin{array}{c}\mathrm{H} \\
\text { concentration } \\
(\text { at. \% })^{\mathrm{a}}\end{array}$ & $\begin{array}{c}\text { Crystalline size } \\
(\mathrm{nm})\end{array}$ & $\begin{array}{c}\text { Surface to } \\
\text { volume atom } \\
\text { ratio }(\%)^{\mathrm{b}}\end{array}$ \\
\hline HF CVD (1 h) & $1.2 \times 10^{20}$ & 0.12 & 300 & 0.5 \\
HF CVD (10 min) & $6 \times 10^{20}$ & 0.6 & 50 & 3 \\
MW-CVD-3-20 nm & $6.1 \times 10^{21}$ & 6.1 & $3-20$ & $50-7.5$ \\
MW-CVD-10-30 nm & $5.1 \times 10^{21}$ & 5.1 & $10-30$ & $15-5$ \\
dc-GD-CVD-5 nm & $1.45 \times 10^{22}$ & 14.5 & 5 & 28 \\
\hline \hline
\end{tabular}

${ }^{\mathrm{a}}$ Assuming a $\mathrm{C}$ concentration of $1 \times 10^{23}$ at. $\mathrm{cm}^{-3}$.

${ }^{b}$ Surface to volume atom ratio of fcc crystallite with the same crystalline size. 
$1350 \mathrm{~cm}^{-1} D$ line and the $1580 \mathrm{~cm}^{-1} G$ line), whose relative intensity depends on diamond crystal size, grain quality, etc. ${ }^{36-39}$ For nanodiamond films additional features around 1140 and $1480 \mathrm{~cm}^{-1}$ are commonly observed. ${ }^{37,40-45}$ It was shown by $\operatorname{Raman}^{37,43}$ and surface enhanced Raman spectroscopies ${ }^{44}$ that these peaks are associated with $\nu_{1}$ and $\nu_{3}$ vibration modes of trans-polyacetylene $(t-\mathrm{PA})$ codeposited with diamond phase. The $1140 \mathrm{~cm}^{-1}$ Raman peak is associated most likely with a $\mathrm{C}-\mathrm{H}$ bending mode of hydrogenated $s p^{2}$ carbon bonded to diamond grain internal surfaces and boundaries. Our studies of dc GD CVD nanodiamond film evolution on hydrogenated graphitic/ amorphous carbon precursor clearly show that this mode is absent from the spectrum of hydrogenated carbon of a predominant graphitic character ( $\sim 20$ min deposition) and appears only when nanodiamond crystallites precipitate in dense hydrogenated amorphous carbon matrix $(\sim 30 \mathrm{~min}$ deposition). ${ }^{45}$ Since hydrogen concentration nearly scales with diamond grain surface ratio (Sec. III A), it strongly suggests that this mode is related to diamond phase itself, e.g., belongs to $s p^{2}$ carbon bonded to diamond grain internal surfaces. Our work on thermal stability of carbon-hydrogen bonding ${ }^{45}$ provides a direct evidence that $1140 \mathrm{~cm}^{-1}$ Raman mode is stable up to temperatures typically high for hydrogen desorption from diamond grains (up to $1000{ }^{\circ} \mathrm{C}$ ). On the other hand, nearly all kinds of hydrogenated carbon with different $s p^{2} / s p^{3}$ ratios decompose at temperatures up to $\sim 600{ }^{\circ} \mathrm{C}$. In Sec. III C, we correlate this Raman mode with $\left(s p^{2}\right)-\mathrm{C}-\mathrm{H}$ stretching vibration detected by HR-EELS.

The hydrogen bonding and the crystalline nature of the different films were characterized by Raman (Fig. 3). Spectra 3(a) and 3(b) correspond to the MW CVD films grown for $1 \mathrm{~h}$, samples MW-CVD-3-20 nm and MW-CVD10-30 nm, respectively. Spectra 3(c) and 3(d) were measured on the HF CVD diamond films grown for $10 \mathrm{~min}$ $[\sim 100 \mathrm{~nm}$ film thickness, $3(\mathrm{c})]$ and $60 \mathrm{~min}[\sim 700 \mathrm{~nm}$ thickness, 3(d))] (their SEM micrographs were shown in Fig. 1). Spectrum 3(e) corresponds to the dc GD CVD film grown for $60 \mathrm{~min}$. Besides spectrum 3(d), all spectra display most of the characteristic Raman modes of nanodiamond films discussed previously: two broad peaks at $\sim 1350$ ( $D$ peak) and $1530 \mathrm{~cm}^{-1}$ ( $G$ peak), 1140 and $1480 \mathrm{~cm}^{-1}$, associated with nanodiamond. Spectra 3(c) and 3(d) display an additional peak positioned at $1332 \mathrm{~cm}^{-1}$ characteristic to diamond. Spectrum 3(d) was measured on a thick HF CVD diamond film and is attributed to high quality diamond film. Here, the diamond peak at $\sim 1332 \mathrm{~cm}^{-1}$ is sharp, well pronounced, and large compared to the background contributions of the $s p^{2}$-related $D$ and $G$ peaks, reflecting the much larger diamond crystalline size, reduced grain boundary, and defects densities. The $t$-PA vibrational modes at 1140 and $1480 \mathrm{~cm}^{-1}$ are practically absent, indicating much smaller amount of $\mathrm{C}-\mathrm{H}$ bonding at grain boundaries in comparison with the $100 \mathrm{~nm}$ thick HF CVD film.

It was shown above that the three different classes of diamond films follow the same tendency: the smaller grain size results in the higher hydrogen retention. It is possible, therefore, to associate the shape of the Raman spectrum with diamond grain size and hydrogen content therein. The high

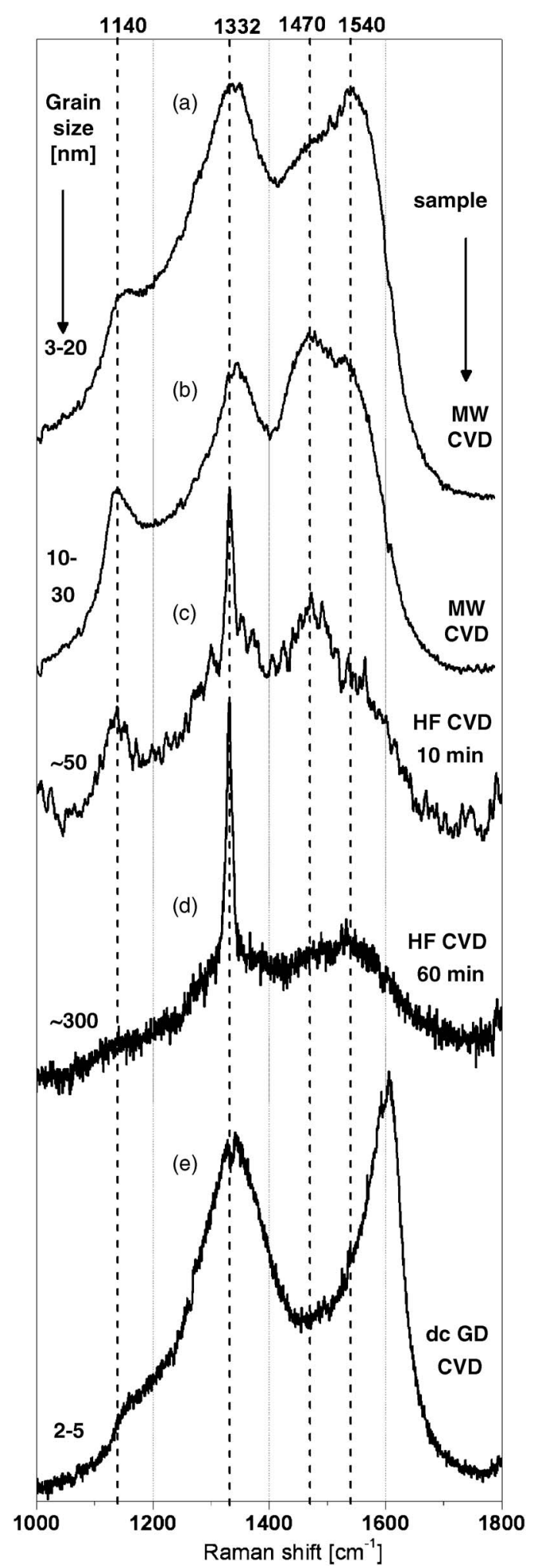

FIG. 3. Raman spectra of the different diamond samples. (a) MW CVD sample with grain size of 3-20 nm. (b) MW CVD sample with grain size of 10-30 nm. (c) HF CVD diamond film deposited for $10 \mathrm{~min}(\sim 50 \mathrm{~nm}$ grain size). (d) HF CVD diamond film deposited for $1 \mathrm{~h}$ ( $\sim 300 \mathrm{~nm}$ grain size). (e) dc GD CVD diamond film deposited for $1 \mathrm{~h}(\sim 5 \mathrm{~nm}$ grain size).

hydrogen concentration results in appearance of pronounced $t$-PA associated Raman modes at 1140 and $1480 \mathrm{~cm}^{-1}$. In addition, the sharp diamond optical phonon mode at $1332 \mathrm{~cm}^{-1}$ is broadened for grain size smaller than $50 \mathrm{~nm}$ and for $10-30 \mathrm{~nm}$ crystallites, the graphitic $D$ peak at 
$1350 \mathrm{~cm}^{-1}$ appears. For the smallest grain size [e.g., $\sim 5 \mathrm{~nm}$ in the case of dc GD nanodiamond films, spectrum 3 (e)], however, the intensity of $1140 \mathrm{~cm}^{-1}$ is diminished relative to carbon associated $D$ and $G$ peaks in comparison with spectra 3(b) and 3(c). From the SIMS measurements described above, the dc GD nanodiamond film contains the highest (among the investigated films) concentration of trapped hydrogen.

Our results suggest that for diamond films composed of crystallites of $\sim 5 \mathrm{~nm}$, the intensity of carbon-hydrogen associated peaks is diminished relative to the pure carboncarbon modes. Additional evidence of this phenomenon comes from HR-EELS measurements of $\mathrm{C}-\mathrm{H}$ stretching vibrations of these films, as described in the following section. A similar tendency was found in IR measurements of diamond $\mathrm{C}-\mathrm{H}$ stretching mode as a function of diamond grain size. ${ }^{46-48}$ The intensity of $\mathrm{C}-\mathrm{H}$ stretching mode at $2834 \mathrm{~cm}^{-1}$ decreases with decreasing diamond grain size $(350 \rightarrow 5 \mathrm{~nm})$. In that case, the proposed explanation of this phenomenon (based on density functional calculations) was associated with the absence of well-defined facets on the surface of $5 \mathrm{~nm}$ size diamond crystallites. ${ }^{46,47}$

We conclude that the shape of the Raman spectrum is strongly affected by diamond grain size (and, therefore, by hydrogen atom concentration within the film). While the spectrum of the film consists of diamond grains with the size of a few hundred nanometers is dominated by diamond optical phonon loss at $1332 \mathrm{~cm}^{-1}$ with minor contribution from mixed $s p^{2} / s p^{3}$ carbon (the band near $1500 \mathrm{~cm}^{-1}$ ), the smaller diamond crystallites result in enhanced $s p^{2}$-carbon-hydrogen peaks near 1140 and $1480 \mathrm{~cm}^{-1}$. However, this tendency is reversed for the smaller grain size of $\sim 5 \mathrm{~nm}$ : in this case, the intensity of these peaks decreases and the spectrum is dominated by graphitic $D$ and $G$ peaks at 1350 and $1580 \mathrm{~cm}^{-1}$. In addition, reducing grain size may affect the complex bonding configuration of carbon atom within the film, namely, $s p^{2} / s p^{3}$ ratio, the ordering of $s p^{2}$ component, etc., not just the amount of hydrogen atoms bonded to $s p^{2}$ hybridized carbon. The physical explanation of this phenomenon is under current investigation in our laboratory.

\section{Hydrogen bonding configuration on diamond film surface studied by high resolution electron energy loss spectroscopy}

Different HR-EELS modes of diamond surface were recently studied by us by means of isotopic substitution of hydrogen by deuterium as well as ${ }^{12} \mathrm{C}$ by ${ }^{13} \mathrm{C} .{ }^{49,50}$ We refer to the spectrum presented in Fig. 4(a) as the basic hydrogenated diamond HR-EEL spectrum. The different vibrational modes are enumerated on the plot. Mode 1 at $\sim 155 \mathrm{meV}$ is a superposition of a $\mathrm{C}-\mathrm{C}$ stretch and a $\mathrm{C}-\mathrm{H}$ bending vibrations (the later shifts to $108 \mathrm{meV}$ upon replacement of $\mathrm{H}$ by D). The energy loss peaks around 300 and $450 \mathrm{meV}$ (modes 2 and 4 ) are pure $\mathrm{C}-\mathrm{C}$ vibrations, most likely the first and second overtones of the diamond optical phonon positioned at $150 \mathrm{meV} .^{49,50}$ Peak 3 at $\sim 360 \mathrm{meV}$ is attributed to $\mathrm{C}-\mathrm{H}$ stretching mode, while peak 5 at $\sim 510 \mathrm{mV}$ is a coupled $\mathrm{C}-\mathrm{H}$ stretch mode positioned at $\sim 360$ and $\sim 155 \mathrm{meV}$ po- sitioned bands. The nature of these peaks and their sensitivity to ion beam damage were recently investigated by us. ${ }^{51}$

We start with the analysis of $\mathrm{C}-\mathrm{H}$ stretching mode of as-deposited HF CVD diamond film (grain size of $\sim 300 \mathrm{~nm}$ ) as a function of thermal annealing. In Fig. 4, the HR-EEL spectra of HF CVD diamond sample are shown as a function of annealing temperature. The shape of the spectra is nearly unaffected by $T<800{ }^{\circ} \mathrm{C}$, while $T=1000{ }^{\circ} \mathrm{C}$ results in elimination of hydrogen associated features (360 and $510 \mathrm{meV}$ peaks) and addition of $\sim 90 \mathrm{meV}$ peak associated with $\mathrm{C}=\mathrm{C}$ dimer. EEL spectra (primary energy $E_{p}$ $=500 \mathrm{eV}$ ) of the same film as a function of the same annealing temperatures are shown in Fig. 5. Diamond plasmon losses are nearly unaffected by heating at $T<800{ }^{\circ} \mathrm{C}$, while heating at $T=1000{ }^{\circ} \mathrm{C}$ results in appearance of graphitic $\pi$ electrons ( $\sim 6 \mathrm{eV}$ energy loss). Note the correlation between hydrogen desorption detected by HR-EELS at $T_{A}=1000{ }^{\circ} \mathrm{C}$ (Fig. 4) and graphitic feature appearance detected by EELS (Fig. 5). Hydrogen desorption at elevated temperature results in rearrangement of carbon bonds and appearance of $\mathrm{C}=\mathrm{C}$ dimer ( $~ 90 \mathrm{meV}$ on HR-EEL spectrum). These dimers may form graphitic monolayer on the top of diamond surface, which contribute to $6 \mathrm{eV}$ graphitic $\pi$-plasmon losses, detected by EELS.

The detailed peak fitting procedure of $\mathrm{C}-\mathrm{H}$ stretching HR-EELS mode [Fig. 4(b)] reveals at least three different contributions at $\sim 350, \sim 360$, and $\sim 373 \mathrm{meV}$. The first two are most likely associated with diamond (111) and (100) surfaces, ${ }^{52}$ while the last one may be attributed to $s p^{2}$-hybridized carbon. ${ }^{53,54}$ This assignment is being verified at the present time by performing HR-EELS measurements on (100) and (111) single crystal surfaces in our system for internal calibration of the vibrational spectra. However, for the purpose of the present analysis, it is sufficient to associate the 350 and $360 \mathrm{meV}$ modes with hydrogen atoms bonded to $s p^{3} \mathrm{C}$ and this is certainly the case. ${ }^{52}$ Upon annealing to $800{ }^{\circ} \mathrm{C}$, the maximum peak position is slightly shifted to smaller loss energies (from 359 to $357 \mathrm{meV}$ ), while the $s p^{2}$-associated mode at $\sim 373 \mathrm{meV}$ is still prominent. According to thermal stability studies of different kinds of hydrogenated amorphous carbon matrices, ${ }^{55-61}$ annealing to a temperature of $>600{ }^{\circ} \mathrm{C}$ results in desorption of hydrogen atoms alongside with hydrocarbon species, independent of the method used for amorphous carbon film preparation. This allows us to attribute the $373 \mathrm{meV}$ HR-EELS mode to hydrogen bonded to $s p^{2}$-hybridized carbon positioned at diamond grain surface and boundary, which may be stable up to these high temperatures. This suggestion may be confirmed by HR-EELS studies of the nanodiamond film discussed below.

Now, we turn to analyze the vibrational modes on the surface of nanodiamond films deposited by MW CVD. Figure 6 shows the EEL spectra of the MW-CVD-3-20 nm film recorded at primary electron energy $E_{p}=500 \mathrm{eV}$ before and after ex situ MW hydrogenation. Both spectra are dominated by characteristic diamond losses, namely, bulk and surface diamond plasmons at 33 and $23 \mathrm{eV}$, correspondingly. It can be concluded from the comparison of the spectra of asdeposited films and the ex situ MW hydrogenated films that 
Energy Loss $\left[\mathrm{cm}^{-1}\right]$

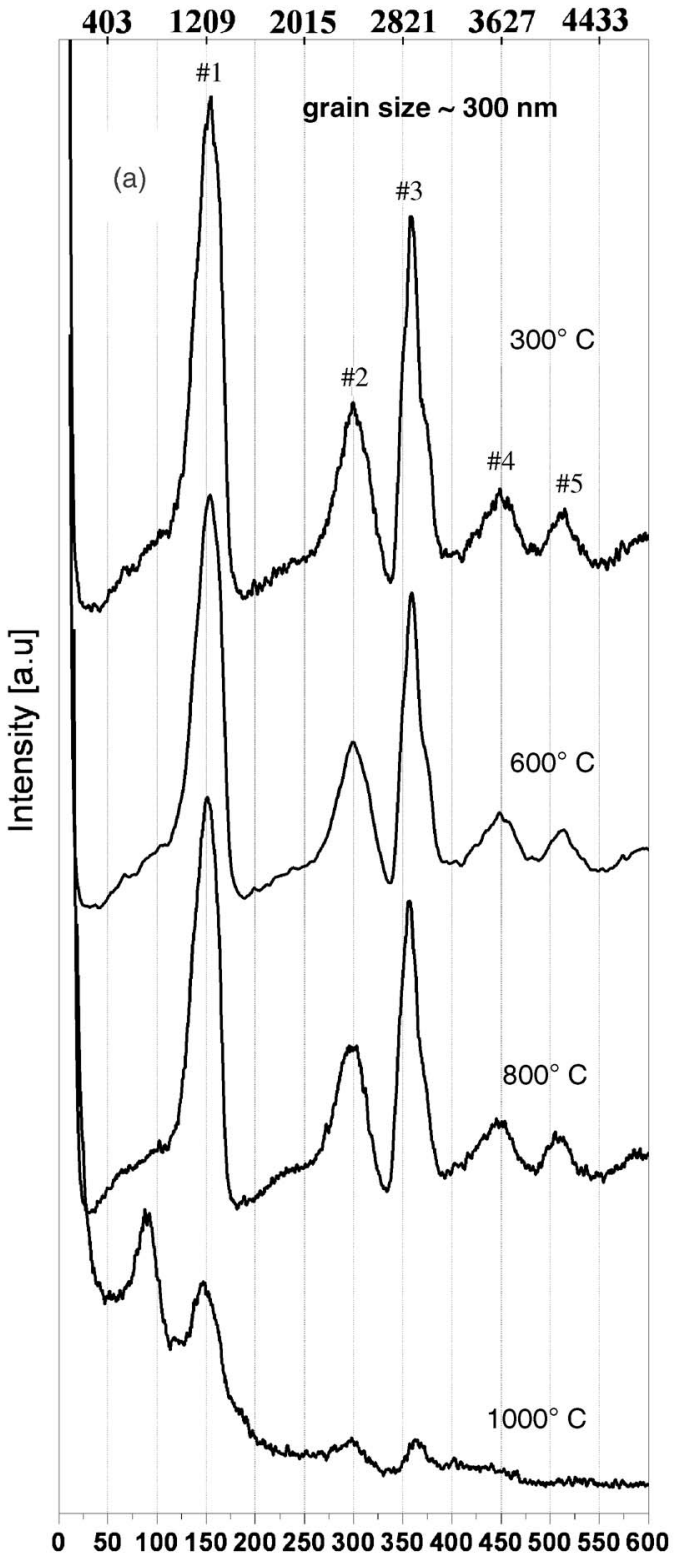

Energy Loss [meV]

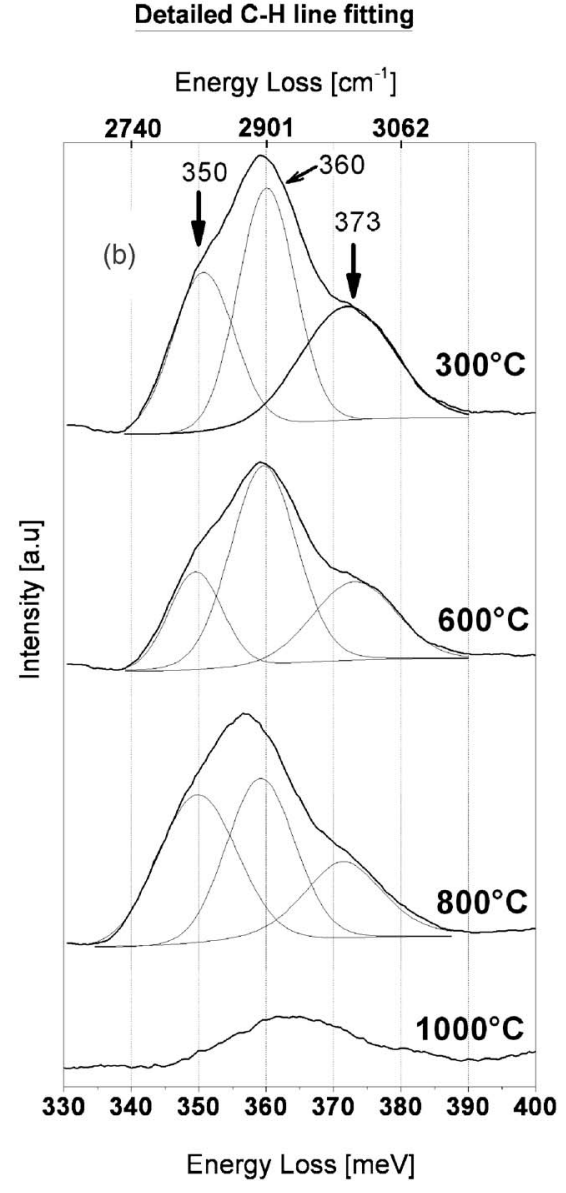

FIG. 4. (a) HR-EEL spectra of asdeposited HF CVD films as a function of annealing temperature. The primary electron energy was $5 \mathrm{eV}$ and FWHM of elastic peak was 7-8 meV. The shape of the spectrum is nearly unchanged up to $T_{A}=800{ }^{\circ} \mathrm{C}$. The $T_{A}$ $=1000{ }^{\circ} \mathrm{C}$ results in complete hydrogen desorption (the absence of $\sim 360 \mathrm{meV}$ peak) alongside with appearance of $\mathrm{C}=\mathrm{C}$ dimer mode at $\sim 90 \mathrm{meV}$. (b) Detailed analysis of HR-EELS $\mathrm{C}-\mathrm{H}$ stretching mode of as-deposited HF CVD diamond film [data were taken from spectrum (a)]. Peak fitting procedure reveals three different contributions at $\sim 350$, $\sim 360$, and $\sim 375 \mathrm{meV}$ energy losses. ex situ MW hydrogenation results in increasing intensity of the diamond surface plasmon at $23 \mathrm{eV}$, which may be associated with etching of amorphous carbon component present on the surface of as-deposited film. The direct evidence of this fact comes from HR-EELS analysis of these samples discussed below.

HR-EEL spectra of the MW-CVD-3-20 nm nanodiamond film deposited by MW CVD are shown in Fig. 7. The upper line [Fig. 7(a)] corresponds to the as-deposited sample following UHV annealing to $700{ }^{\circ} \mathrm{C}$. Detailed analysis of $\mathrm{C}-\mathrm{H}$ stretching mode is shown in Fig. 7(d). The spectrum 7(a) is dominated by a mixed $\mathrm{C}-\mathrm{C}$ stretching and $\mathrm{C}-\mathrm{H}$ bending mode at $155 \mathrm{meV}$, the overtones of the diamond optical phonon at 300 and $450 \mathrm{meV}$, and $\mathrm{C}-\mathrm{H}$ stretching vibration at $360-375 \mathrm{meV}$. Note the strong splitting of $\mathrm{C}-\mathrm{H}$ stretching mode in this spectrum: the two maxima are positioned at $\sim 360$ and $\sim 375 \mathrm{meV}$, reflecting hydrogen bonding to $s p^{3}$ and $s p^{2}$ carbons, correspondingly [spectrum 7(d)]. Following MW hydrogenation and subsequent UHV annealing to $630{ }^{\circ} \mathrm{C}$ [spectrum $\left.7(\mathrm{~b})\right]$ the diamond overtones underwent enhancement relative to $\mathrm{C}-\mathrm{H}$ associated modes. The splitting of $\mathrm{C}-\mathrm{H}$ stretching vibrations disappears and now, this mode is centered at $360 \mathrm{meV}$ indicating preferential etching of $s p^{2}$ carbon by atomic hydrogen [only $s p^{3}$ $\mathrm{C}-\mathrm{H}$ modes are present, spectrum $7(\mathrm{e})]$. We conclude, therefore, that ex situ exposure to atomic hydrogen results in preferential etching of $s p^{2}$ carbon leaving well-defined diamond surface with hydrogenation. Annealing to $1000{ }^{\circ} \mathrm{C}$ results in hydrogen desorption and appearance of $\sim 90 \mathrm{meV}$ peak $(\mathrm{C}=\mathrm{C}$ dimer) in a similar way as for HF CVD diamond films with $\sim 300 \mathrm{~nm}$ grain size (cf. Fig. 4).

Now, we compare the HR-EELS analysis of as-deposited MW CVD nanodiamond [spectra 7(a) and 7(d)] with the asdeposited HF CVD submicron crystalline samples (Fig. 4). As can be seen in Fig. 4(b), the HR-EEL spectrum of asdeposited HF CVD films with $\sim 300 \mathrm{~nm}$ grains also displays 


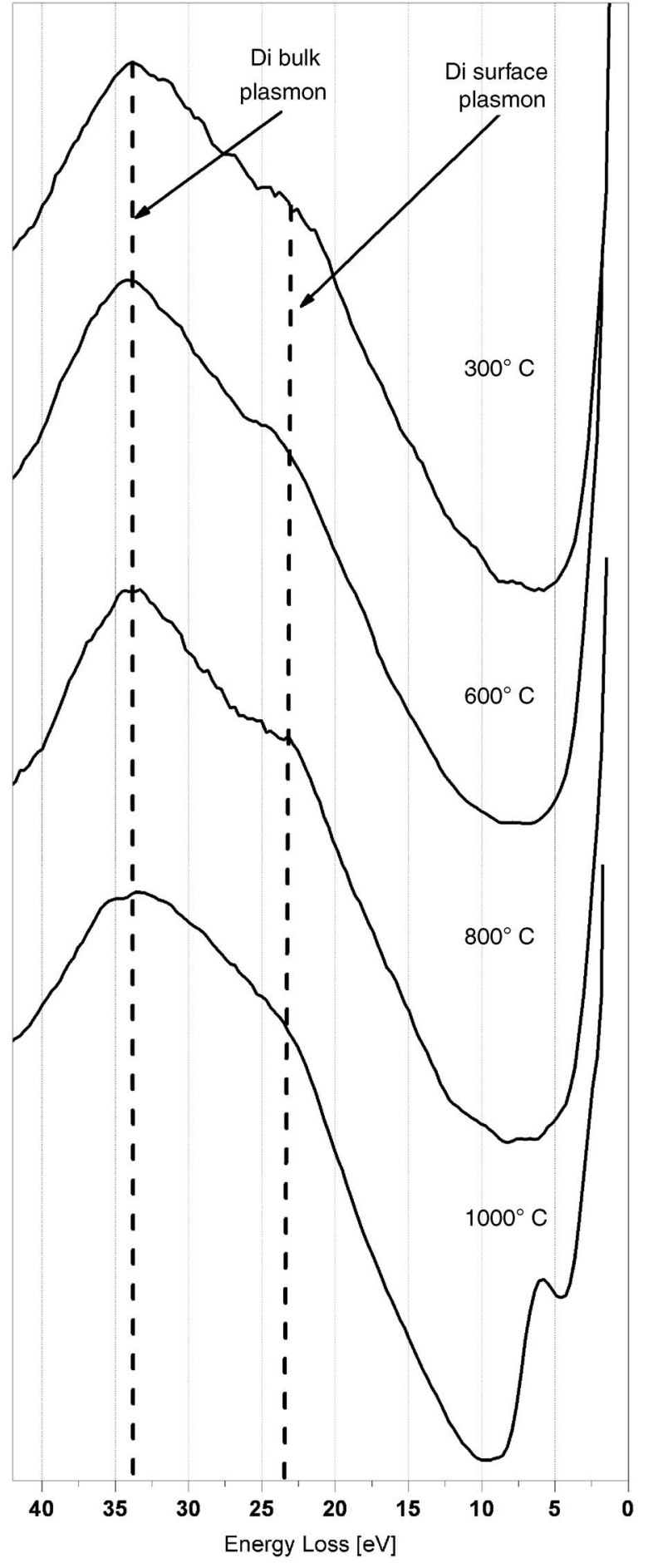

FIG. 5. EEL spectra of HF CVD diamond films as a function of annealing temperature. Primary electron energy $E_{p}=500 \mathrm{eV}$. The shape of the spectrum is nearly unchanged up to annealing temperature $T_{A}=800{ }^{\circ} \mathrm{C}$, while $T_{A}=1000{ }^{\circ} \mathrm{C}$ results in appearance of the graphitic $\pi \rightarrow \pi^{*}$ associated plasmon at $\sim 6 \mathrm{eV}$. Note the correlation of this graphitic feature with hydrogen desorption detected by HR-EEL spectroscopy.

contributions at $\sim 350, \sim 360$, and $\sim 375 \mathrm{meV}$ within the $\mathrm{C}-\mathrm{H}$ stretching modes which are stable up to $700{ }^{\circ} \mathrm{C}$. Similar annealing experiments performed on MW-CVD$10-30 \mathrm{~nm}$ sample $^{62}$ show that the $375 \mathrm{meV}$ mode is stable up to at least $800^{\circ} \mathrm{C}$. Obviously, the ratio of grain boundaries in the case of nanodiamond films (3-20 nm grains) exceeds that of submicron crystallites $(\sim 300 \mathrm{~nm}$ grains).

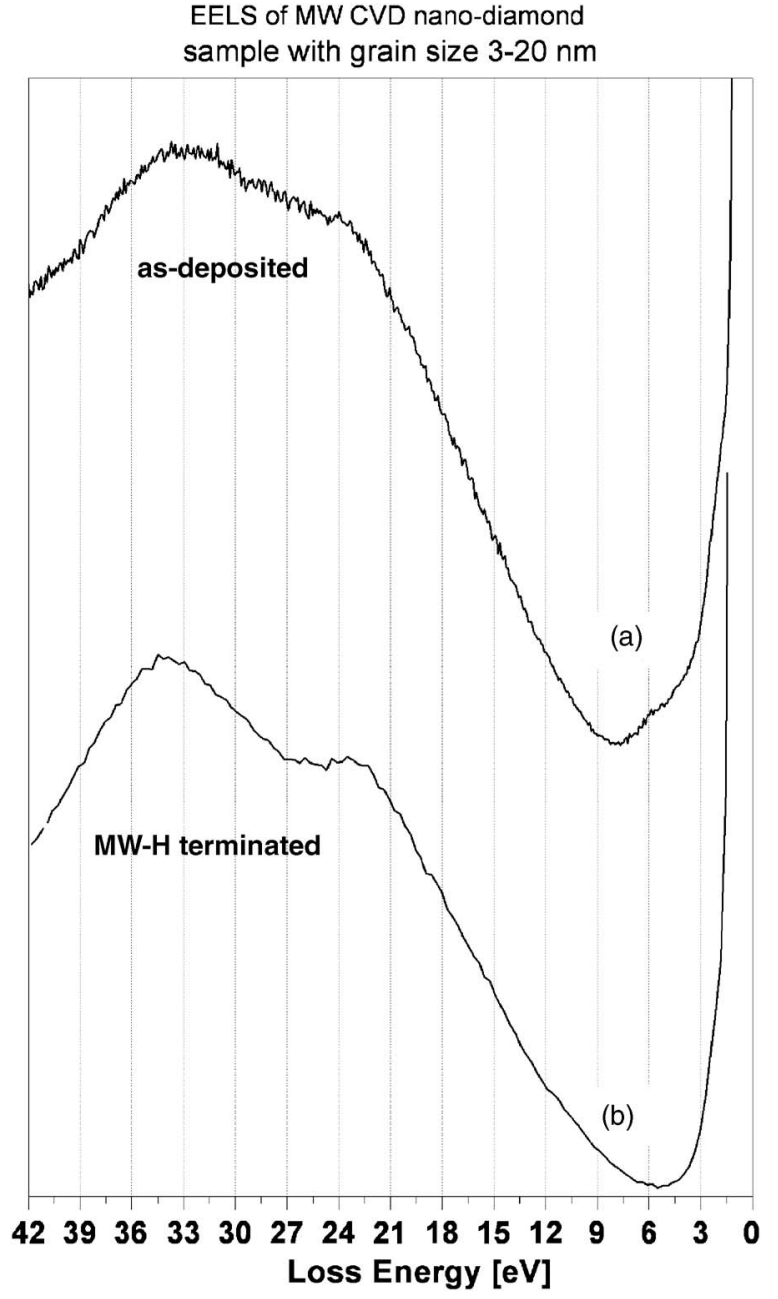

FIG. 6. EEL spectra of MW CVD nanodiamond film with grain size of 3-20 nm. The primary electron energy $E_{p}=500 \mathrm{eV}$. (a) As-deposited sample annealed to $700{ }^{\circ} \mathrm{C}$. (b) Ex situ MW-H terminated sample annealed to $630{ }^{\circ} \mathrm{C}$. Note the enhancement of diamond surface plasmon at energy loss of $23 \mathrm{eV}$ following ex situ MW hydrogenation.

Since the contribution of the $\sim 375$ meV mode is much more prominent in the case of nanometric grains, this mode may be associated with hydrogen bonded to the surface and grain boundary of the nanodiamond film. This is a very exciting feature. In our studies of hydrogen adsorption on ion irradiated diamond surface, ${ }^{51}$ we concluded that nearly all kinds of hydrogenated carbon decompose near $\sim 600^{\circ} \mathrm{C}$. This is in agreement with other studies of thermal stability of diamondlike carbon which undergoes erosion/destabilization at temperature of $<600{ }^{\circ} \mathrm{C}$ independently of deposition process. ${ }^{55-61}$ The present results show that $s p^{2}$-hybridized carbon is stable up to temperatures above $800{ }^{\circ} \mathrm{C}$. This finding allows one to distinguish the hydrogenated $s p^{2}$-hybridized carbon bonded to diamond grains from chemi-(or physi)sorbed molecules on polycrystalline diamond surface by simple annealing procedure.

It is very interesting to note at this stage the possible correlation between the $\sim 375 \mathrm{meV}$ HR-EELS mode and the well-known Raman $1140 \mathrm{~cm}^{-1}$ peak of nanodiamond. It was shown in the works of many authors, ${ }^{36,37,43,44}$ including us, ${ }^{20}$ that the $1140 \mathrm{~cm}^{-1}$ Raman peak is attributed to $\mathrm{C}-\mathrm{H}$ bending mode of $s p^{2}$ carbon and positioned most likely in the 


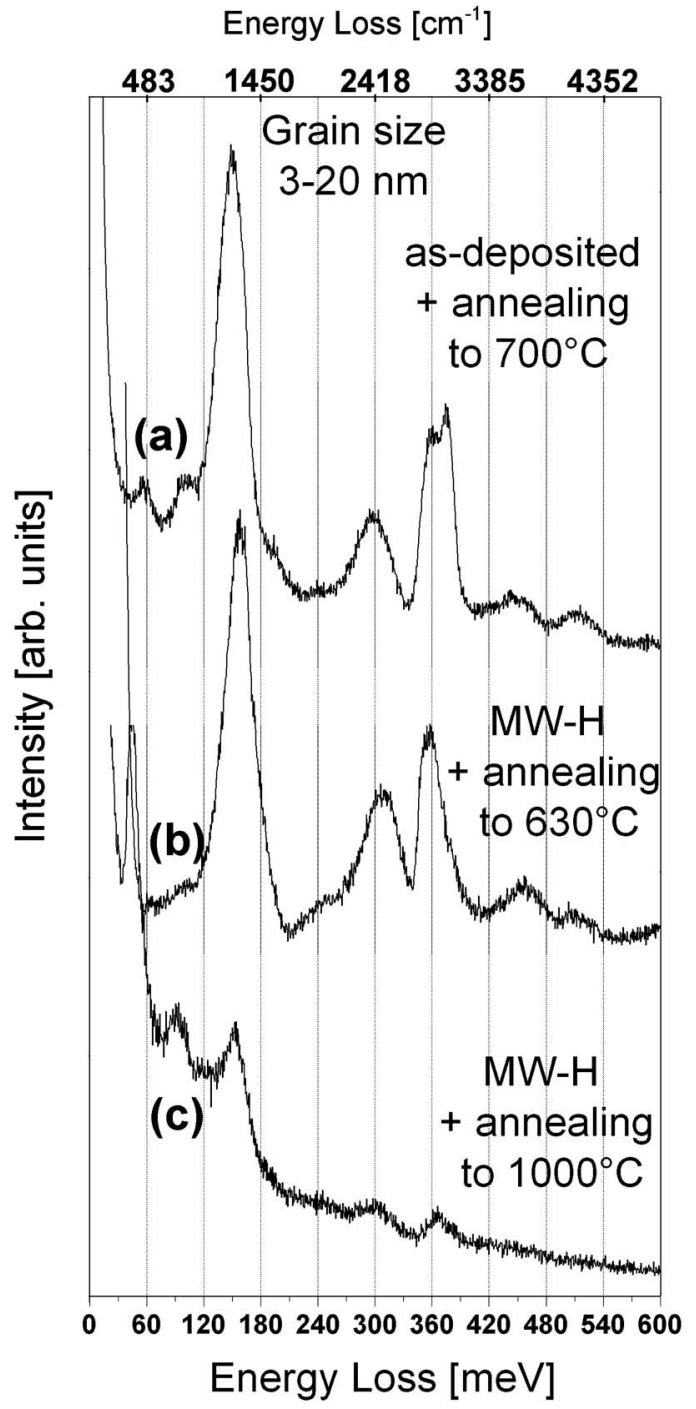

\section{Detailed $\mathrm{C}-\mathrm{H}$ line fitting}

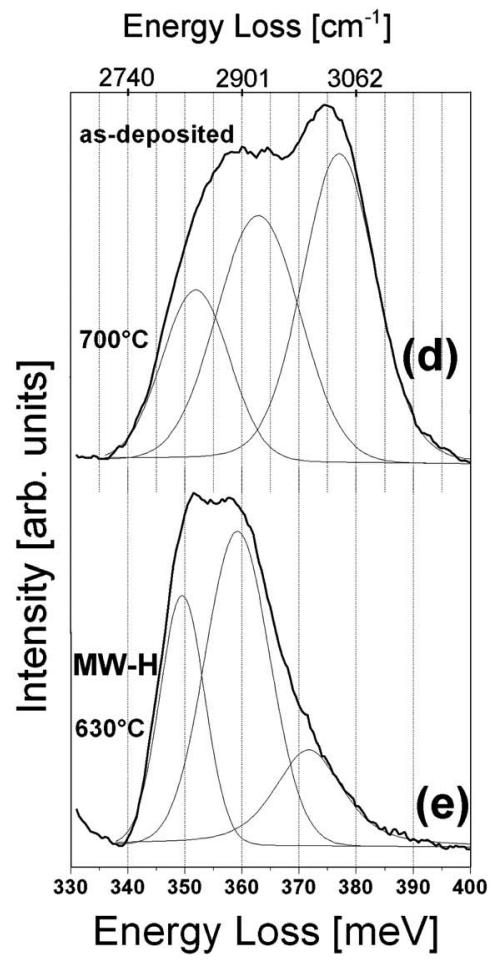

FIG. 7. HR-EEL spectra of MW CVD deposited nanodiamond films. (a) Asreceived sample annealed to $700^{\circ} \mathrm{C}$. (b) As-deposited sample following MW-H treatment for 15 min and subsequent annealing to $630^{\circ} \mathrm{C}$. (c) Followed further annealing to $1000^{\circ} \mathrm{C}$. [(d) and (e)] Detailed analysis of HREELS $\mathrm{C}-\mathrm{H}$ stretching mode [data originated from spectra (a) and (b)]. diamond grain boundary. Both peaks (Raman $1140 \mathrm{~cm}^{-1}$ and HR-EELS $\sim 375 \mathrm{meV}$ mode) are attributed to $\left(s p^{2}\right)$ carbon-hydrogen vibration. Both peaks are stable up to elevated temperatures, ${ }^{45}$ where hydrogen bonded to amorphous carbon undergoes desorption. Both peaks are strongly enhanced in the case of nanodiamond grains. Therefore, our results strongly suggest that the $\sim 375 \mathrm{meV}$ mode can be attributed to the stretching of the same $\mathrm{C}-\mathrm{H}$ vibration, which contributes to the $1140 \mathrm{~cm}^{-1}$ Raman peak (currently attributed to $\nu_{1}$ mode of $t$-PA, the bending of $s p^{2} \mathrm{C}-\mathrm{H}$ ). Both peaks may serve as an indication of nanocrystalline character of diamond films. However, due to different probing depths of Raman and HR-EEL spectroscopies (tens or hundreds of nanometers in the case of Raman and 1-2 nm in the case of HR-EELS), quantitative comparison of these two peaks is impossible. It should be stressed that this assignment of the $375 \mathrm{meV}$ peak is circumstantial; a computational study of this mode is in progress in our laboratory.

The HR-EEL spectra of nanodiamond films are different from those of submicron grain size films in the relative intensities of $\mathrm{C}-\mathrm{C}$ related modes relative to $\mathrm{C}-\mathrm{H}$ vibrations. Figure 8 shows a comparison between the HR-EEL spectra measured for the three kinds of diamond films grown for $1 \mathrm{~h}$ by different methods: HF CVD, dc GD CVD, and MW CVD. In order to compare these spectra, all films were exposed to the same ex situ surface treatment in MW hydrogen plasma for $\sim 10 \mathrm{~min}$. Since the first strong peak at $\sim 155 \mathrm{meV}$ is composed of mixed $\mathrm{C}-\mathrm{C}$ and $\mathrm{C}-\mathrm{H}$ modes, we should compare only pure $\mathrm{C}-\mathrm{C}$ vibration modes with pure $\mathrm{C}-\mathrm{H}$ modes, namely, overtones of diamond optical phonon at $300 \mathrm{meV}$ with $\mathrm{C}-\mathrm{H}$ stretching mode at $360 \mathrm{meV}$. In the case of HF CVD (grain size of $\sim 300 \mathrm{~nm}$ ), the relative ratio of intensity of $360 \mathrm{meV}$ mode with respect to the intensity of $300 \mathrm{meV}$ phonon overtone is 1.88 . In the case of nanodiamond films deposited by MW CVD (grain size lies in 3-20 nm range), the same ratio is 1.2 , while for dc GD CVD nanodiamond films (grains of $\sim 5 \mathrm{~nm}$ ), this ratio is $\sim 0.9$. This ratio is correlated with diamond grain size, namely, the smaller the diamond grain is, the smaller ratio of the intensity of the pure $\mathrm{C}-\mathrm{H} / \mathrm{C}-\mathrm{C}$ associated modes is. This sensitivity of the HR-EEL spectrum of nanodiamond compared to that of microcrystalline diamond is speculated to be associated with the shorter elastic mean free path of the scattered electrons in the former. ${ }^{63}$ This is expected considering the larger density of internal grain boundaries in the nanosized grain films compared to that of the micron-size 


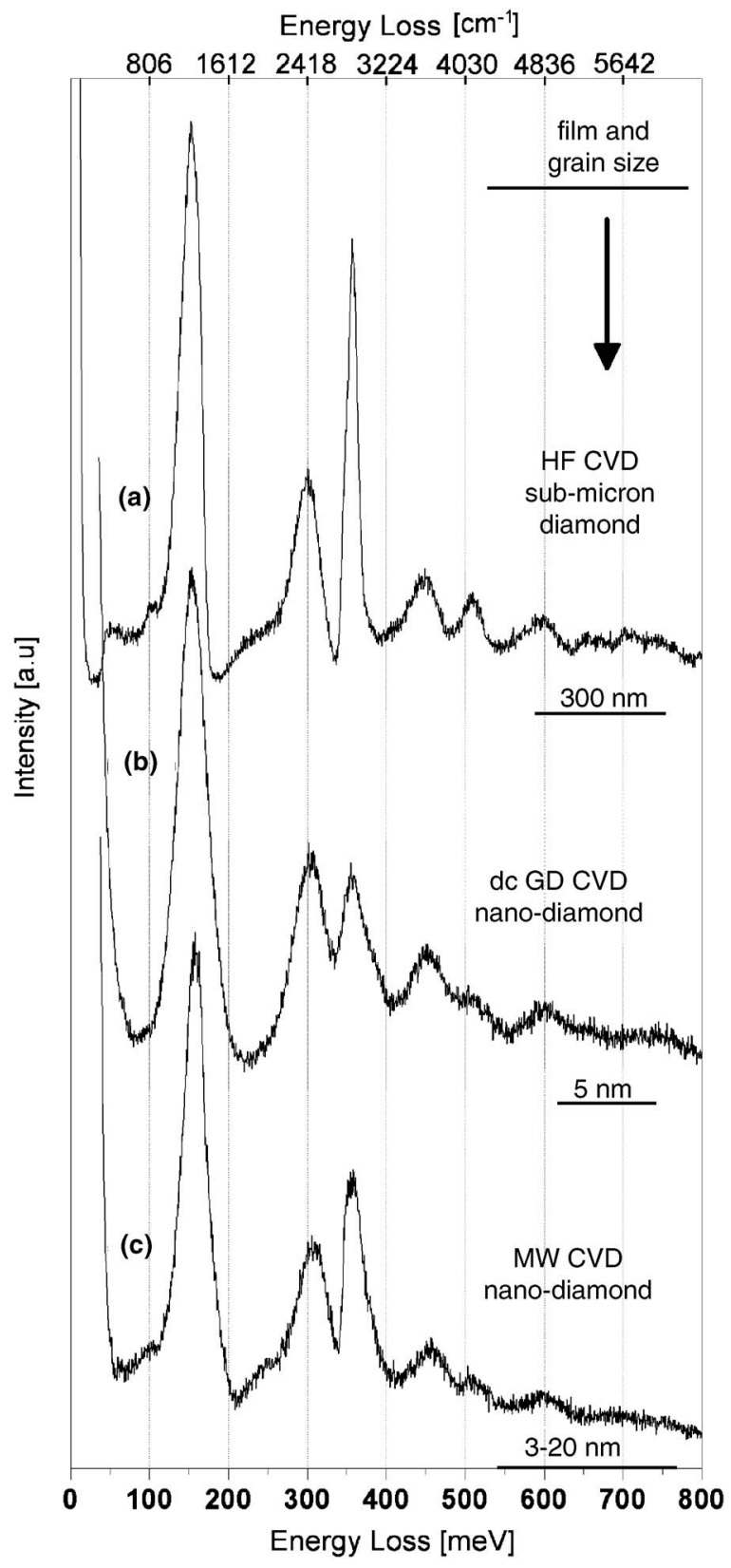

FIG. 8. Comparison of HR-EEL spectra of three different diamond films which underwent MW-H treatment: (a) HF CVD film grown for $1 \mathrm{~h}$ (grain size of $\sim 300 \mathrm{~nm}$ ), (b) nanodiamond film grown by dc GD method (grain size of $\sim 5 \mathrm{~nm}$ ), and (c) MW CVD sample (grain size of 3-20 nm). Note the different ratios of $\mathrm{C}-\mathrm{C}$ associated modes relative to $\mathrm{C}-\mathrm{H}$ vibrations.

ones. The shorter mean free path will results in a larger elastic backscattering cross section thus, resulting in an enhancement of the losses associated with the sub-surface region for the case of nanodiamond-as indeed observed: the relative intensity of the $155 \mathrm{meV}$ mode (and $300 \mathrm{meV}$ ) compared to that of the $\sim 360 \mathrm{meV}$ mode is larger for nanodiamond than that for microcrystalline diamond. These very delicate points are under investigation in our laboratory at the present time.

We conclude, therefore, that the diamond grain size impacts the shape of HR-EEL spectra. Hydrogen bonding to surfaces and grain boundaries of nanodiamond films displays a clear contribution to the HR-EELS at $\sim 375 \mathrm{meV}$ which differs from bonding to the microcrystalline diamond sur- faces, whose main contribution is centered around $360 \mathrm{meV}$. The $\sim 375 \mathrm{meV}$ mode is stable up to elevated temperatures of $\sim 800{ }^{\circ} \mathrm{C}$, where all kinds of hydrogenated amorphous carbon are decomposed. The intensity of this mode is drastically decreased following ex situ treatment in MW activated hydrogen plasma, most likely due to preferential etching of $s p^{2}$ carbon bonded to diamond grain surfaces and boundaries. In addition, the spectrum of the fully hydrogenated diamond surface (ex situ exposed to atomic hydrogen plasma) shows a decrease of $\mathrm{C}-\mathrm{H}$ associated modes relative to pure $\mathrm{C}-\mathrm{C}$ modes. The last phenomena are correlated with our Raman data (Sec. III B) as well as with IR measurements reported by others. ${ }^{46-48}$ Detailed investigation of this phenomenon is under current investigation in our laboratory.

\section{SUMMARY}

In this paper, we investigated the impact of diamond grain size on the hydrogen bonding configuration and retention in polycrystalline diamond films deposited by three different chemical vapor deposition methods. The films were grown from hydrogen rich gas mixtures (hot filament and dc GD CVD) and Ar rich/hydrogen poor gas mixture (MW CVD). SIMS studies provide direct evidence of the correlation between the concentration of hydrogen atom trapped within the films and the diamond grain size, independent of deposition conditions: the smaller diamond grains result in higher hydrogen atom retention within the films. The hydrogen atoms are most likely bonded to the internal grain surfaces and within the grain boundary region. High hydrogen concentration in nanodiamond films has impact on the shape of the Raman and HR-EEL spectra of nanodiamond films. Thus, the carbon-hydrogen associated $1140 \mathrm{~cm}^{-1}$ Raman peak $(\mathrm{C}-\mathrm{H}$ bending mode) undergoes enhancement in the case of nanocrystalline films alongside with HR-EELS $375 \mathrm{meV} \mathrm{C}-\mathrm{H}$ stretching mode. Based on thermal stability studies, we associate these vibrational modes with $\left(s p^{2}\right)$ $\mathrm{C}-\mathrm{H}$ vibration originated from diamond surfaces and grain boundaries. HR-EELS $\mathrm{C}-\mathrm{H}$ associated peaks undergo intensity decrease relative to pure carbon vibrational modes in the case of ultrananocrystalline diamond (grain size of $\sim 5 \mathrm{~nm}$ ). A possible explanation is offered to elucidate this effect.

\section{ACKNOWLEDGMENTS}

This research project was carried out with the financial support of the Israeli Academy of Science, the Israeli Ministry of Science and Arts, and the Technion Fund for Promotion of Research.

${ }^{1}$ S. Y. Luo, J. K. Kuo, B. Yeh, J. C. Sung, C. W. Dai, and T. J. Tsai, Mater. Chem. Phys. 72, 133 (2001).

${ }^{2}$ L. Y. Huang, K. W. Xu, J. Lu, and B. Guelorget, Surf. Coat. Technol. 154, 232 (2002).

${ }^{3}$ N. Jiang, K. Sugimoto, K. Nishimura, Y. Shintani, and A. Hiraki, J. Cryst. Growth 242, 362 (2002).

${ }^{4}$ K. H. Wu, X. R. Wang, S. Liu, and E. G. Wang, J. Appl. Phys. 90, 4810 (2001).

${ }^{5}$ N. G. Ferreira, L. L. G. Silva, and E. J. Corat, Diamond Relat. Mater. 11, 657 (2002).

${ }^{6}$ Q. Y. Chen, D. M. Gruen, A. R. Krauss, T. D. Corrigan, M. Witek, and G. 
M. Swain, J. Electrochem. Soc. 148, E44 (2001).

${ }^{7}$ J. Q. Li, D. Y. He, W. T. Guo, J. H. Zhang, Y. N. Sun, Q. S. Lei, and X. Gao, Int. J. Mod. Phys. B 16, 1013 (2002).

${ }^{8}$ W. B. Yang, F. X. Lu, and Z. X. Cao, J. Appl. Phys. 91, 10068 (2002).

${ }^{9}$ S. Bhattacharyya, O. Auciello, J. Birrell, J. A. Carlisle, L. A. Curtiss, A. N. Goyette, D. M. Gruen, A. R. Krauss, J. Schlueter, A. Sumant, and P. Zapol, Appl. Phys. Lett. 79, 1441 (2001).

${ }^{10}$ D. M. Gruen, Annu. Rev. Mater. Sci. 29, 211 (1999).

${ }^{11}$ Y. Lifshitz, Th. Kohler, Th. Frauenheim, I. Guzmann, A. Hoffman, R. Q. Zhang, X. T. Zhou, and S. T. Lee, Science 297, 1531 (2002).

${ }^{12}$ J. B. Cui, J. Ristein, and L. Ley, Phys. Rev. Lett. 81, 429 (1998).

${ }^{13}$ I. L. Krainsky, V. M. Asnin, G. T. Mearini, and J. A. Dayton, Phys. Rev B 53, R7650 (1996)

${ }^{14}$ J. Ristein, F. Maier, M. Riedel, M. Stammer, and L. Ley, Diamond Relat. Mater. 10, 416 (2001)

${ }^{15}$ O. Ternyak, A. Cimmino, S. Prawer, and A. Hoffman, Diamond Relat. Mater. 14, 272 (2005).

${ }^{16}$ O. Ternyak, Sh. Michaelson, R. Akhvlediani, and A. Hoffman, Diamond Relat. Mater. 15, 850 (2006).

${ }^{17}$ W. Zhu, G. P. Kochanski, and S. Jin, Science 282, 1471 (1998).

${ }^{18}$ P. Ascarelli, E. Cappelli, F. Pinzari, M. C. Rossi, S. Salvatori, P. G. Merli, and A. Migliori, J. Appl. Phys. 89, 689 (2001).

${ }^{19}$ Sh. Michaelson, O. Ternyak, Y. Lifshitz, and A. Hoffman, Appl. Phys. Lett. 90, 031914 (2007).

${ }^{20}$ Sh. Michaelson, Y. Lifshitz, O. Ternyak, and A. Hoffman, Appl. Phys. Lett. 89, 131918 (2006).

${ }^{21}$ P. Reichart, G. Datzmann, A. Hauptner, R. Hertenberger, C. Wild, and G. Dollingeer, Science 306, 1537 (2004).

${ }^{22}$ M. Benlahsen, B. Racine, K. Zellama, and G. Turban, J. Non-Cryst. Solids 47, 283 (2001)

${ }^{23}$ B. Racine, M. Benlahsen, K. Zellama, P. Goudeau, M. Zarrabian, and G Turban, Appl. Phys. Lett. 73, 3226 (1998).

${ }^{24}$ J. Robertson, Philos. Mag. Lett. 57, 143 (1988)

${ }^{25}$ J. Robertson, Phys. Rev. Lett. 68, 220 (1992).

${ }^{26}$ W. Jacob, Thin Solid Films 326, 1 (1998).

${ }^{27}$ P. Reinke, W. Jacob, and W. Moller, J. Appl. Phys. 74, 1354 (1993).

${ }^{28}$ A. Hoffman, A. Heiman, R. Akhvlediani, E. Lakin, E. Zolotoyabko, and C. Cyterman, J. Appl. Phys. 94, 4589 (2003).

${ }^{29}$ E. Titus, D. S. Misra, A. K. Sikder, P. K. Tyagi, M. K. Singh, A. Misra, N. Ali, G. Cabral, V. F. Neto, and J. Gracio, Diamond Relat. Mater. 14, 476 (2005).

${ }^{30}$ D. F. Talbot-Ponsonby, M. E. Newton, J. M. Baker, G. A. Scarsbrook, R. S. Sussmann, A. J. Whitehead, and S. Pfenningen, Phys. Rev. B 57, 2264 (1998).

${ }^{31}$ R. D. Maclear, J. E. Butler, S. H. Connell, B. P. Doyle, I. Z. Machi, D. B. Rebuli, J. P. F. Sellschop, and E. Sideras-Haddad, Diamond Relat. Mater. 8, 1615 (1999).

${ }^{32}$ Y. Lifshitz, X. M. Meng, S. T. Lee, R. Akhvlediani, and A. Hoffman, Phys. Rev. Lett. 93, 056101 (2004).

${ }^{33}$ R. Akhvlediani, I. Lior, Sh. Michaelson, and A. Hoffman, Diamond Relat. Mater. 11, 545 (2002).

${ }^{34}$ D. Zhou, D. M. Gruen, L. C. Qin, T. G. McCauley, and A. R. Krauss, J. Appl. Phys. 84, 1981 (1998).

${ }^{35}$ Sh. Michaelson, Y. Lifshitz, O. Ternyak, R. Akhvlediani, and A. Hoffman,
Diamond Relat. Mater. 16, 845 (2007).

${ }^{36}$ A. C. Ferrari and J. Robertson, Phys. Rev. B 63, 121405(R) (2001).

${ }^{37}$ A. C. Ferrari and J. Robertson, Philos. Trans. R. Soc. London, Ser. A 362, 2477 (2004)

${ }^{38}$ A. C. Ferrari, S. E. Rodil, and J. Robertson, Diamond Relat. Mater. 12, 905 (2003)

${ }^{39}$ N. Wada, P. J. Gaczi, and S. A. Solin, J. Non-Cryst. Solids 35-6, 543 (1980).

${ }^{40}$ R. J. Nemanich, J. T. Glass, G. Lukovsky, and R. E. Shreder, J. Vac. Sci. Technol. A 6, 1783 (1988)

${ }^{41}$ R. E. Shroder, R. J. Nemanich, and J. T. Glass, Phys. Rev. B 41, 3738 (1990).

${ }^{42}$ W. A. Yarbrough and R. Messier, Science 247, 688 (1990).

${ }^{43}$ H. Kuzmany, R. Pfeiffer, N. Salk, and B. Günther, Carbon 42, 911 (2004).

${ }^{44}$ T. Lopez-Rios, D. Mendoza, F. J. Garcia-Vidal, J. Sanchez-Dehesa, and B. Pannetier, Phys. Rev. Lett. 81, 665 (1998).

${ }^{45} \mathrm{Sh}$. Michaelson and A. Hoffman, Diamond Relat. Mater. 15, 486 (2006).

${ }^{46}$ C.-F. Chen, C.-C. Wu, C.-L. Cheng, S.-Y. Sheu, and H.-C. Chang, J. Chem. Phys. 116, 1211 (2002).

${ }^{47}$ Y.-R. Chen, H.-C. Chang, C.-L. Cheng, C.-C. Wang, and J. C. Jiang, J. Chem. Phys. 119, 10626 (2003).

${ }^{48}$ C.-L. Cheng, C.-F. Chen, W.-C. Shaio, D.-S. Tsai, and K.-H. Chen, Diamond Relat. Mater. 14, 1455 (2005).

${ }^{49}$ Sh. Michaelson, Y. Lifshitz, and A. Hoffman, Appl. Phys. Lett. 89, 223112 (2006).

${ }^{50}$ Sh. Michaelson, Y. Lifshitz, and A. Hoffman, Diamond Relat. Mater. 16, 855 (2007).

${ }^{51}$ M. Bertin, A. Lafosse, R. Azria, Sh. Michaelson, O. Ternyak, and A. Hoffman, Appl. Phys. Lett. 90, 061918 (2007).

${ }^{52}$ T. Aizawa, T. Ando, K. Yamamoto, M. Kamo, and Y. Sato, Diamond Relat. Mater. 4, 600 (1995).

${ }^{53}$ J. Ristein, R. T. Stief, L. Ley, and W. Beyer, J. Appl. Phys. 84, 3836 (1998).

${ }^{54}$ Th. Frauenheim, Th. Kohler, M. Sternberg, D. Porezag, and M. R. Pederson, Thin Solid Films 272, 314 (1996).

${ }^{55}$ R. Kalish, Y. Lifshitz, K. Nugent, and S. Prawer, Appl. Phys. Lett. 74, 2936 (1999).

${ }^{56} \mathrm{R}$. Kalish, The Physics of Diamond, International School of Physics Enrico Fermi Vol. 135, edited by A. Paoletti and A. Tucciarone (IOS, Amsterdam, 1997), p. 373.

${ }^{57}$ M. Benlahsen, B. Racine, K. Zellama, and G. Turban, J. Non-Cryst. Solids 283, 47 (2001).

${ }^{58}$ Ch. Wild and P. Koidl, Appl. Phys. Lett. 51, 1506 (1987).

${ }^{59}$ J. K. Walters, D. M. Fox, T. M. Burke, O. D. Weedon, R. J. Newport, and W. S. Howells, J. Chem. Phys. 101, 4288 (1994).

${ }^{60}$ J. K. Walters, J. S. Rigden, R. J. Newport, S. F. Parker, and W. S. Howells, Phys. Scr., T 57, 142 (1995)

${ }^{61}$ M. Lejeune, M. Benlahsen, and R. Bouzerar, Appl. Phys. Lett. 84, 344 (2004).

${ }^{62}$ Sh. Michaelson, O. Ternyak, A. Hoffman, O. A. Williams, and D. M. Gruen, Appl. Phys. Lett. 91, 103104 (2007).

${ }^{63}$ V. Richter, B. Fizgeer, Sh. Michaelson, A. Hoffman, and R. Kalish, J. Appl. Phys. 96, 5824 (2004) 